This work is licensed under a Creative Commons Attribution 3.0 License.

\author{
Research article
}

\title{
Review of Neurepyris Kieffer, 1905 (Hymenoptera, Bethylidae), a new synonym of Pristocera Klug, 1808
}

Alencar I.D.C.C. \& Azevedo C.O. 2011. Review of Neurepyris Kieffer, 1905 (Hymenoptera, Bethylidae), a new synonym of Pristocera Klug, 1808. European Journal of Taxonomy 4: 1-12. http://dx.doi.org/10.5852/ejt.2011.4

\author{
Isabel D.C.C. ALENCAR ${ }^{1,3}$ \& Celso O. AZEVEDO ${ }^{2}$ \\ ${ }^{1}$ Instituto Federal de Educação, Ciência e Tecnologia do Espírito Santo, Campus Santa Teresa, \\ Rodovia ES-080, km 21, 29660-000 Santa Teresa, ES, Brasil. \\ ${ }^{2}$ Universidade Federal do Espírito Santo, Departamento de Biologia, \\ Av. Marechal Campos,1468, 29.040-090, Vitória, ES, Brasil \\ 32Email: idccalencar@gmail.com
}

\begin{abstract}
The genus Neurepyris Kieffer, 1905 is revised. The adult male holotypes N. rufiventer Kieffer, 1913 from Eritrea and N. tagala (Ashmead, 1905) from the Philippines are redescribed and illustrated. Both species are transferred from the subfamily Epyrinae to Pristocerinae because they have the metanotum well developed medially. Neurepyris rufiventer is transferred to Pristocera Klug, 1808 because the hypopygium is deeply divided into two apical lobes, the subdiscoidal and cubital veins do not reach the border of the forewing, the pronotal disc has the anterior region slightly elevate medially, and the stigma is elongate. Neurepyris tagala is transferred to Apenesia Westwood, 1874 because the basal tooth of mandible is not curved inward, the median lobe of clypeus is not depressed near the antennal insertions, and the aedeagus consists of one lamina. The genus Neurepyris is considered a junior synonym of Pristocera because its type species is $N$. rufiventer.
\end{abstract}

Key words. Epyrinae, Pristocerinae, Apenesia, Afrotropical region, Oriental region.

\section{Introduction}

Kieffer (1905) created Neurepyris Kieffer, 1905 to accommodate a species of Epyrini, which has a longitudinal carina on the propodeal disc absent, unidentate tarsal claw and lanceolate stigma. Kieffer \& Marshall's key (1904-1906) indicated that there was one species from Eritrea known from one female, but they did not described in that time. This species was formally described years later as $N$. rufiventer Kieffer, 1913 by Kieffer (1913). Kieffer (1914a) transferred a doubtful Philippine species Rhabdepyris tagala (Ashmead, 1905) to Neurepyris. Both species are known only from their types. However our initial analyses indicate that both species are males of Pristocerinae because both of them have the metanotal well developed medially, propodeum with convex sides, metasoma depressed and genitalia with complex aedeagus.

In this study, we aimed to reconsider the genus, presenting a new view about both species here redescribed and illustrated. 


\section{Material and methods}

The material studied was borrowed from the Museo Civico di Storia Naturale 'Giacomo Doria' - MCSN (F. Penati) and the National Museum of Natural History - USNM (D. Furth).

The nomenclature of integument sculpture follows Harris (1979), and general terms follow Evans (1964) and Azevedo (1999).

Measurements and indices used in this study are as follows: body length measured from the apex of clypeus to the posterior margin of the last metasomal segment; LFW, length of forewing; LH, length of head, measured in frontal view, from vertex crest to median apical margin of clypeus; WH, width of head, measured in frontal view, its maximum width including eyes; WF, width of frons, measured in frontal view, its minimum width, usually about bottom of eyes; HE, height of eye, measured in lateral view, across its maximum height (length); OOL, ocelli-ocular line, measured in latero-dorsal view, the shortest distance from eye top to posterior ocellus; WOT, width of ocellar triangle, measured in frontal view, maximum width, including ocelli; DAO, diameter of anterior ocellus, measured in frontal view; distance of ocellar triangle to vertex: measured in dorso-posterior view, distance from posterior ocellus to vertex crest; VOL, vertex-ocular line, measured in dorsal view, distance from eye top to vertex crest.

\section{Results}

Genus Pristocera Klug, 1808

Neurepyris Kieffer, 1905: 29. Type-species: Neurepyris rufiventer Kieffer, by subsequent monotypy; syn. nov.

Pristocera rufiventer (Kieffer, 1913) comb. nov.

Figs 1-3

Neurepyris rufiventer Kieffer, 1913: 107.

Neurepyris rufiventer - Kieffer 1914a: 370-371. — Gordh \& Móczár 1990: 135.

\section{Material examined}

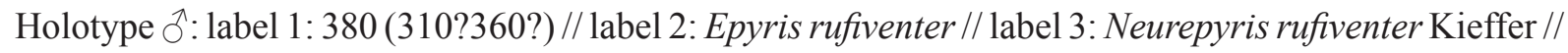
label 4: v. Boll. Lab. Z. Postiei (Portiei) 7, 1913, p.107 // label 5: typus // Label 6: Holotypus, Neurepyris rufiventer, J.J. Kieffer., 1913 // Label 7: Museo Genova, coll. P. magretti (dono 1913).

Penati's note: There is a rhomboid label margined by blue band writing n. 310 attached to locality label (MCSN).

\section{Type-locality}

Eritrea.

\section{Description}

Holotype $\widehat{\jmath}$ (Fig. 1A). Body length $5.8 \mathrm{~mm}$. LFW $4.5 \mathrm{~mm}$.

COLOR. Head and mesosoma black, except pronotal collar and posterior end of pronotal disc dark castaneous, antenna, mandible, tegula and metasoma light castaneous, petiole dark castaneous, legs dark castaneous to light castaneous distally, veins castaneous, pterostigma dark castaneous, wing membrane subhyaline. 

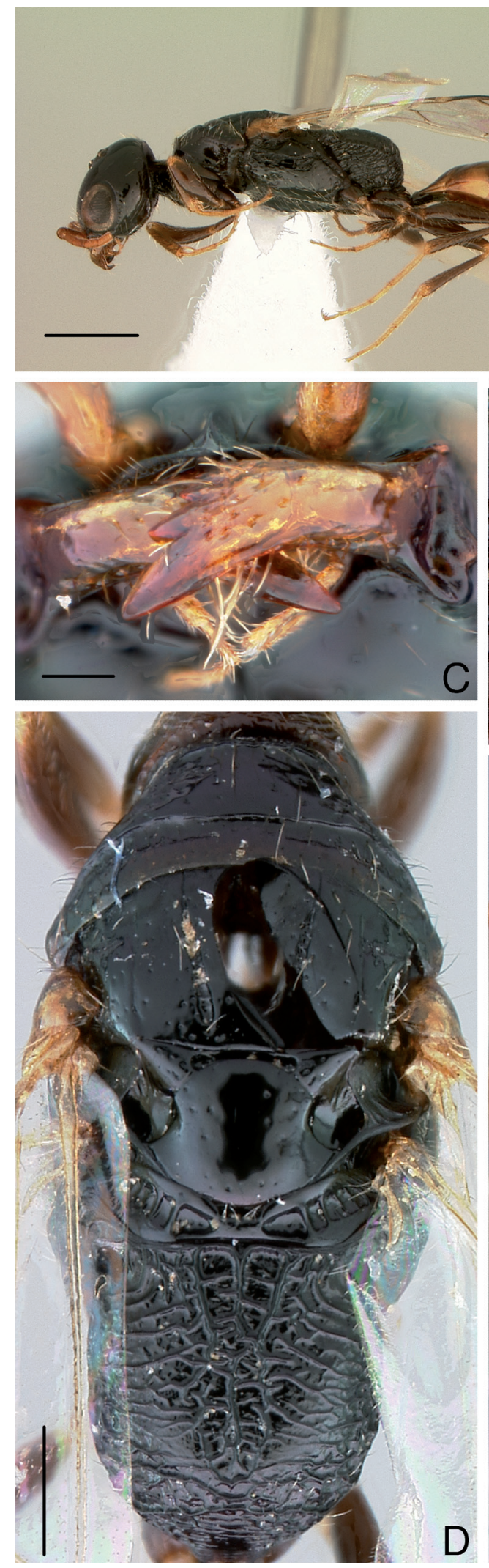

A
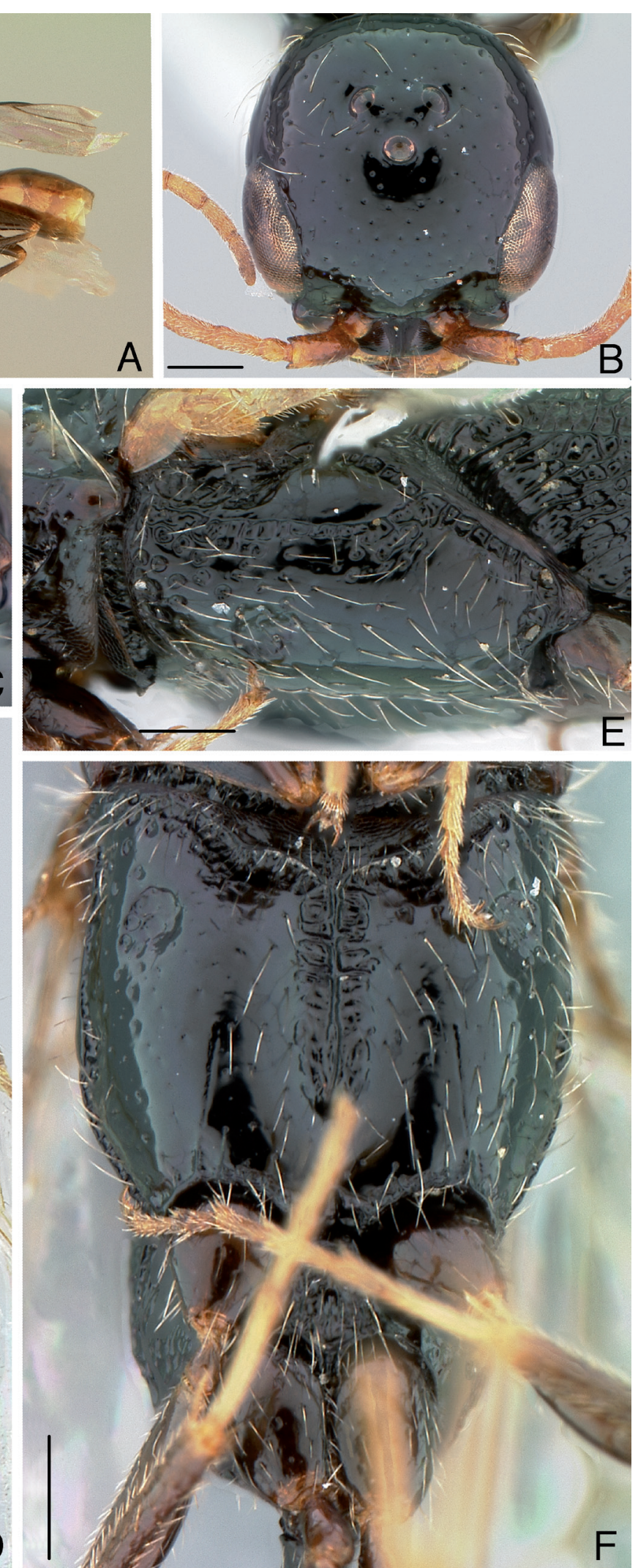

Fig. 1. Pristocera rufiventer comb. nov., holotype, ふૈ. A. Habitus. B. Head, dorsal view. C. Mandible, frontal view. D. Mesosoma, dorsal view. E. Mesopleuron, lateral view. F. Mesosoma, ventral view (bars $0.5 \mathrm{~mm})$. 
HEAD. (Fig. 1B). Mandible with five sharp teeth, upper two reduced (Fig. 1C). Clypeus with truncate median lobe, $0.4 \mathrm{x}$ as long as wide; median carina conspicuous, high and arched in profile. Antenna short, $1.9 \mathrm{~mm}$, reaching posterior end of pronotum; scape arched, widened distad; pubescence sub-appressed with some setae erect, setae long. First four antennomeres in ratio of $\sim 8: 2: 5: 4$; segment XI 2.5x as long as wide. Frons polished, shining, punctate-punctulate. Frontal groove absent. Ocellar triangle elevate, its frontal angle acute, ocelli large. Anterior ocellus surpassing anterad imaginary line of eye top. LH 1.1x WH; WF 0.6x WH; WF 0.9x HE; OOL 1.1x WOT; DAO 0.2x WOT; posterior ocellus distant from vertex crest 3.5x DAO. Profile of vertex crest convex in dorsal view, corner rounded; VOL 1.1x HE. Temple profiles almost parallel in dorsal view. Occipital carina present ventrally and dorsally.

Mesosoma. (Fig. 1D-F). Thorax dorsum shinning, punctulate, setae long. Pronotal disc trapezoidal; side slightly concave; anterior margin carinate; anterior region slightly elevate medially with rounded top. Notaulus conspicuous, incomplete anteriorly, convergent posteriorly, gradually wider and deeper posteriorly, foveolate inside, not reaching posterior margin of mesoscutum. Parapsidal furrow incomplete and inconspicuous anteriorly, straight, narrow, very shallow. Lateral area of mesoscutum slightly elevate without fovea anteriorly. Scutellar groove deep, narrow, concave, dilated laterally. Metanotum with large median elevation; median fovea sub-trapezoidal with anterior base $1.3 \mathrm{x}$ wider than posterior one; metanotal groove foveolate laterally, first fovea very large and triangular, punctulate inside, others rectangular and narrower than first one. Propodeal disc 1.1x as long as wide, disc rugulose; spiracle slightly arched, placed completely at disc. Propodeum rugulose laterally. Propodeal declivity weak, convex in lateral view, rugulose. Mesopleuron with subtegular groove dilated anteriorly and uniformly narrow posteriorly, foveolate inside; episternal groove continuous to subtegular one, foveolate; mesopleural callus elevate, polished and shinning; anterior region strongly punctuate to puncticulate posteriorly, median region with irregular punctures (Fig. 1E); sub-anterior fovea large and deep. Pleurosternum with acetabular carina wide medially followed by large foveae (Fig. 1F); median groove irregularly foveolate; latero-posterior groove narrow, convergent medially. Fore femur 4.2x as long as wide. Tarsal claws bidentate, teeth sharp.

WINGS. (Fig. 2). Forewing with radial vein long and slightly curved forward apically; R1 (metacarpus of Evans) absent; M+Rs (basal vein of Evans) concave; cu-a (transverse vein of Evans) angulate; $\mathrm{Cu} a$ (discoidal vein of Evans) tubular and shortly well pigmented from intersection with $\mathrm{M}+\mathrm{Rs}$; $\mathrm{m}$-cu (first

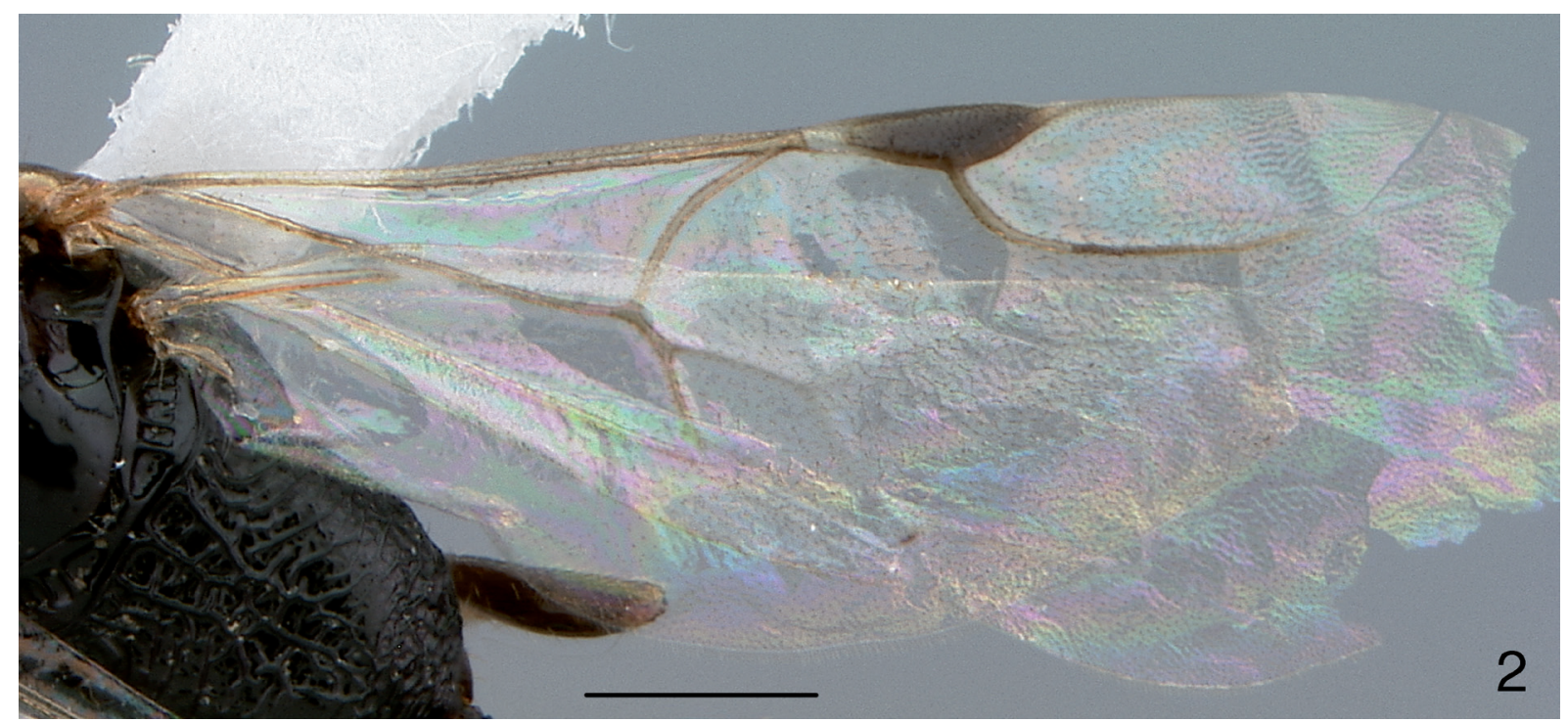

Fig. 2. Pristocera rufiventer comb. nov., holotype, đ̂. Forewing, dorsal view (bar $0.5 \mathrm{~mm}$ ). 
recurrent of Evans) and $\mathrm{Cuc}$ (subdiscoidal vein of Evans) weakly impressed. Hind wing with six apical hamuli.

Metasoma. (Fig. 3A-B). Petiole 0.6x as long as wide. Gaster shinning, puncticulate to imbricatepuncticulate, setose laterally from II tergite. Hypopygium deeply divided (Fig. 3A-B), densely setose apically, base very narrow and apex expanded; inner margin with inner fold setose subapically, base of fold with inner hook rounded mesad.

Genitalia. (Fig. 3C-D): paramere bilaminar, placed ventral-dorsally, 1.5x as long as basiparamere; apex projected upward and arched subapically; apical margin convex; ventral margin with basal fold; dorsal margin slightly concave medially. Basiparamere with dorsal margin slightly concave. Basivolsella surpassing ventral margin of basiparamere, margin almost straight. Digitus with apical margin dentate, apex sharp and arched basad. Cuspis large, narrow, apex concave. Aedeagus divided into two laminae; dorsal lamina with apex divided into two pairs of apical lobes, outer lobe triangular, lateral and dorsal
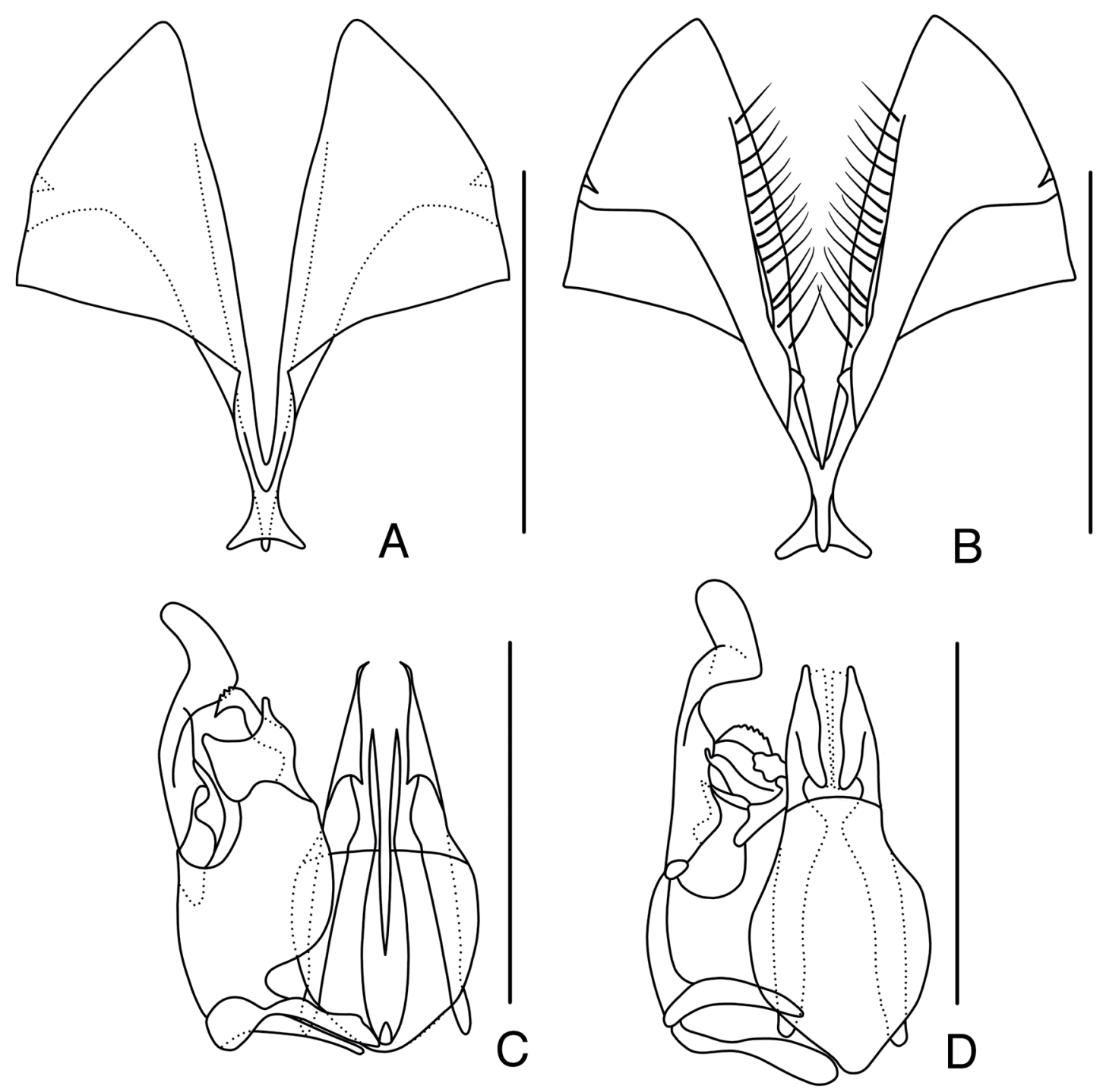

Fig. 3. Pristocera rufiventer comb. nov., holotype, ふૈ. A. Hypopygium, outer view. B. Hypopygium, inner view. C. Genitalia, ventral view. D. Genitalia, dorsal view (bars $0.5 \mathrm{~mm}$ ). 
margin converging upward, apex narrow and projected ventrad, inner lobe membranous; ventral lamina slightly shorter than dorsal one, very narrow, lateral margin convex with subapical constriction, inner margin straight, diverging apicad; ventral margin with basal strap. Genital ring wide laterally. Basal ring absent. Apodeme not extending beyond genital ring.

Genus Apenesia Westwood, 1874

Apenesia tagala (Ashmead, 1905) comb. nov.

Figs 4-6

Epyris tagala Ashmead, 1905: 109.

Rhabdepyris (Trichotepyris) tagala Kieffer, 1908: 32.

Neurepyris tagala Kieffer, 1914a: 370-371.

Epyris tagala - Brown 1906: 68.

Neurepyris tagala - Kieffer 1914b: 285 — Kurian 1954: 273 — Gordh \& Móczár 1990: 135.

\section{Material examined}

Holotype ô: label 1: Manila // Ph; label 2: Robt Brown // Collector; label 3: § Type // No. 8439 // U.S.N.M.; Label 4 (Ashmead's handwritten): Epyris // tagala // ठ̊ Ash. (USNM).

\section{Type-locality}

The Philippines, Luzon, Manila.

\section{Description}

Holotype $\widehat{\jmath}$ (Fig. 4A). Body length $5.1 \mathrm{~mm}$. LFW $3.7 \mathrm{~mm}$.

Color. Head and mesosoma black, except pronotal collar and posterior end of pronotal disc dark castaneous; metasoma dark castaneous; antenna castaneous with flagellomeres progressively darker distad, palpi light castaneous; mandible and tegula castaneous; legs castaneous with coxae darker; wing membrane subhyaline, veins castaneous.

HEAD. (Fig. 4B). Mandible with one lower large tooth and upper cutting edge (Fig. 4C). Clypeus projecting forward subangulate median lobe, its length $0.19 \mathrm{x} \mathrm{LH}$; median carina conspicuous, slightly high and arched in profile. Antenna $1.95 \mathrm{~mm}$ long, reaching posterior end of pronotum; scape arched, widened distad; pubescence suberect with some erect setae. First four antennomeres in ratio of $~ 23: 6: 11: 11$; segment XI 2.25x as long as wide. Eye with sparse short hairs. Frons polished, shining, punctures small, somewhat deep, separated each other by 1.0-3.0x their diameters. Frontal groove absent. LH 1.14x WH; WF 0.52x WH; WF 1.0x HE; frontal angle of ocellar triangle acute; WOT 3.3x DAO, OOL 1.2x WOT; DAO 0.16x WF; posterior ocellus distant from vertex crest 2.3x DAO; anterior margin of anterior ocellus not reaching imaginary top eye line. Profile of vertex crest convex in dorsal view; corner rounded; VOL 0.49x HE. Temple profiles diverging anterad in dorsal view. Occipital carina not visible in dorsal view.

Mesosoma. (Fig. 4D-F). Thorax dorsum shinning, punctures smaller and sparser than those of frons. Pronotal disc trapezoidal; side straight in dorsal view; anterior margin slightly convex, not carinate, pronotal declivity vertical. Notaulus conspicuous, slightly arched, complete anteriorly, convergent posterad, gradually wider posteriorly, not reaching posterior margin of mesoscutum. Parapsidal furrow incomplete anteriorly, conspicuous, slightly arched. Region around parapsidal furrow bulging. Scutellar groove deep, narrow, arched, slightly dilated laterally. Metanotum with median elevation; median fovea semi-circular; metanotal groove foveolate laterally, first fovea large and triangular, not punctured 

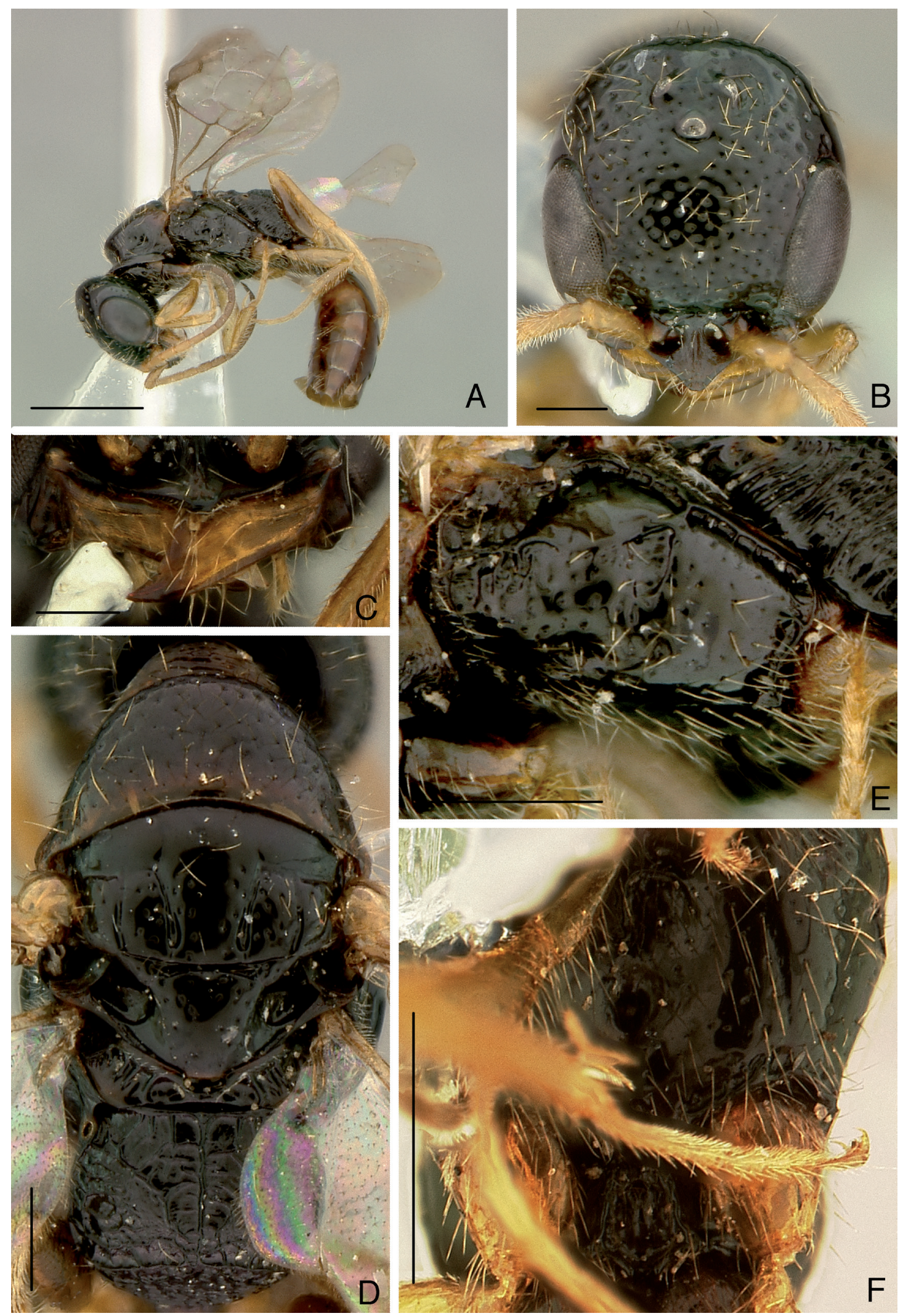

Fig. 4. Apenesia tagala comb. nov., holotype, §ิ. A. Habitus. B. Head, dorsal view. C. Mandible, frontal view. D. Mesosoma, dorsal view. E. Mesopleuron, lateral view. F. Mesosoma, ventral view (bars 0.25 $\mathrm{mm})$. 
inside, others rectangular and narrower than first one. Propodeal disc $0.64 \mathrm{x}$ as long as wide, median carina complete, disc rugulose; spiracle short, elliptical, completely placed at lateral of propodeum, lateral carina abruptly curved anteriorly to accommodate spiracle; posterior carina little distinguishable. Propodeum strigulate laterally. Declivity of propodeum coarsely rugulose, without median carina, almost straight in lateral view. Mesopleuron with subtegular groove dilated anteriorly and evenly narrow posteriorly, foveolate inside; episternal groove not continuous to subtegular one, foveolate; mesopleural callus polished and shinning; anterior region strongly punctuate to puncticulate posteriorly (Fig. 4E). Pleurosternum mostly polished, acetabular carina wide posterior pit deep (Fig. 4F). Fore femur 3.4x as long as wide. Tarsal claws bidentate, teeth sharp.

WiNGS. (Fig. 5). Forewing with radial vein long and evenly curved; R1 short than half length of stigma; $\mathrm{M}+\mathrm{Rs}$ (basal vein of Evans) concave; cu-a (transverse vein of Evans) angulate; $\mathrm{Cu} a$ (discoidal vein of Evans) tubular for short distant, intersecting M+Rs. Hind wing without basal hamuli, with six equidistant median hamuli.

Metasoma. (Fig. 6A-B). Not petiolate; anterior half mostly polished, posterior half mostly very weakly coriaceous; progressively more hairy posterad. Sternite VII rectangular, without median stalk, lateral stalk very short, posterior margin with median narrow semicircular concavity. Hypopygium (Fig. 6AB) strongly concave, but not divided into two lobes, inner margin badly concave, inner surface setose apically, median stalk about $0.6 \mathrm{x}$ as long as plate, lateral stalk very short, dorsal surface short, surrounding inner margin of lobe, progressively higher basad, posterior margin with perpendicular median lamina directed upward.

Genitalia. (Fig. 6C-D): paramere subvertical, about as long as basiparamere; placed dorsally, outer surface mostly hairy, bilaminar, except basal-inner quadrant; apex rounded; wide, dorsal margin much developed mesad, especially basally, basal half convex, apical half concave, with median angulate callus; ventral margin straight. Basiparamere with dorsal margin inclined and truncate in lateral view. Basivolsella completely outlined and separated from basiparamere, short, basal half subquadrate. Digitus laminar, wide, rounded, dorsal surface convex and denticulate. Cuspis laminar, base completely angled upward, somewhat narrow, apex rounded. Aedeagus bulging, divided into dorsal and ventral parts, apex of dorsal one with three pair lobes, dorsal lobe completely angled ventrad, tubular, apex deeply bifurcated; median lobe stout, apical margin with delicate filament apicad, ventral margin denticulate, inner margin membranous and little hairy, ventral lobe with large expansion directed downward; ventral surface laminar expansion, angled laterad with apex rounded and base with ventral loop of irregular

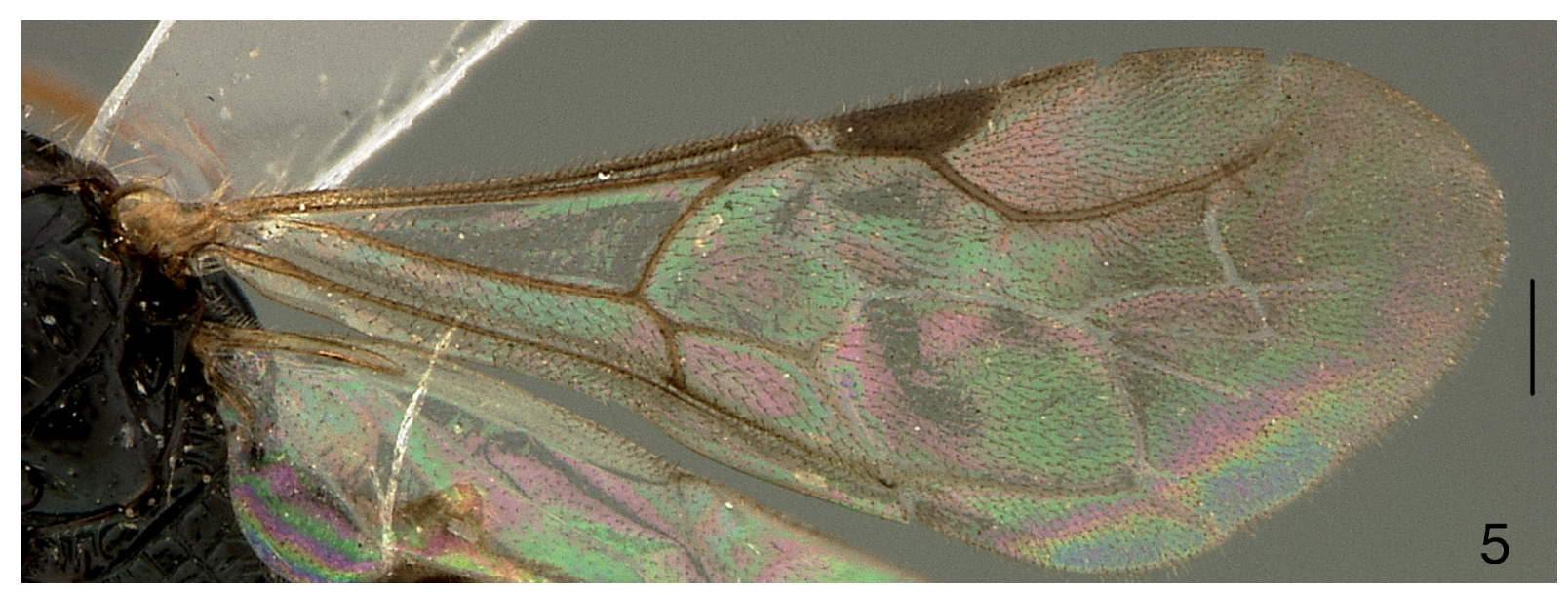

Fig. 5. Apenesia tagala comb. nov., holotype, đ̂. Forewing, dorsal view (bar $0.25 \mathrm{~mm}$ ). 
margin; ventral part of aedeagus laminar with base wider than apex, inner surface vertical, inner lower part with ridge, apex divergent. Genital ring subrectangular. Basal ring narrow. Apodeme narrow, extending beyond genital ring.

\section{Discussion}

According to the most recent Bethylidae catalog (Gordh \& Móczár 1990), Neurepyris type species, Neurepyris tagala, was considered lost but recently Fabio Penati found it in the MCSN collection. Thus, we were able to access it and study both species of the genus. Our results confirm the initial hypothesis that both species of Neurepyris are Pristocerinae. Our analysis also indicated that the only two species belong to distinct genera within Pristocerinae. A historical review of nomenclatural acts of the genus indicated that the type species designation was wrongly perpetuated by Gordh \& Móczár (1990) and its sex was misidentified.
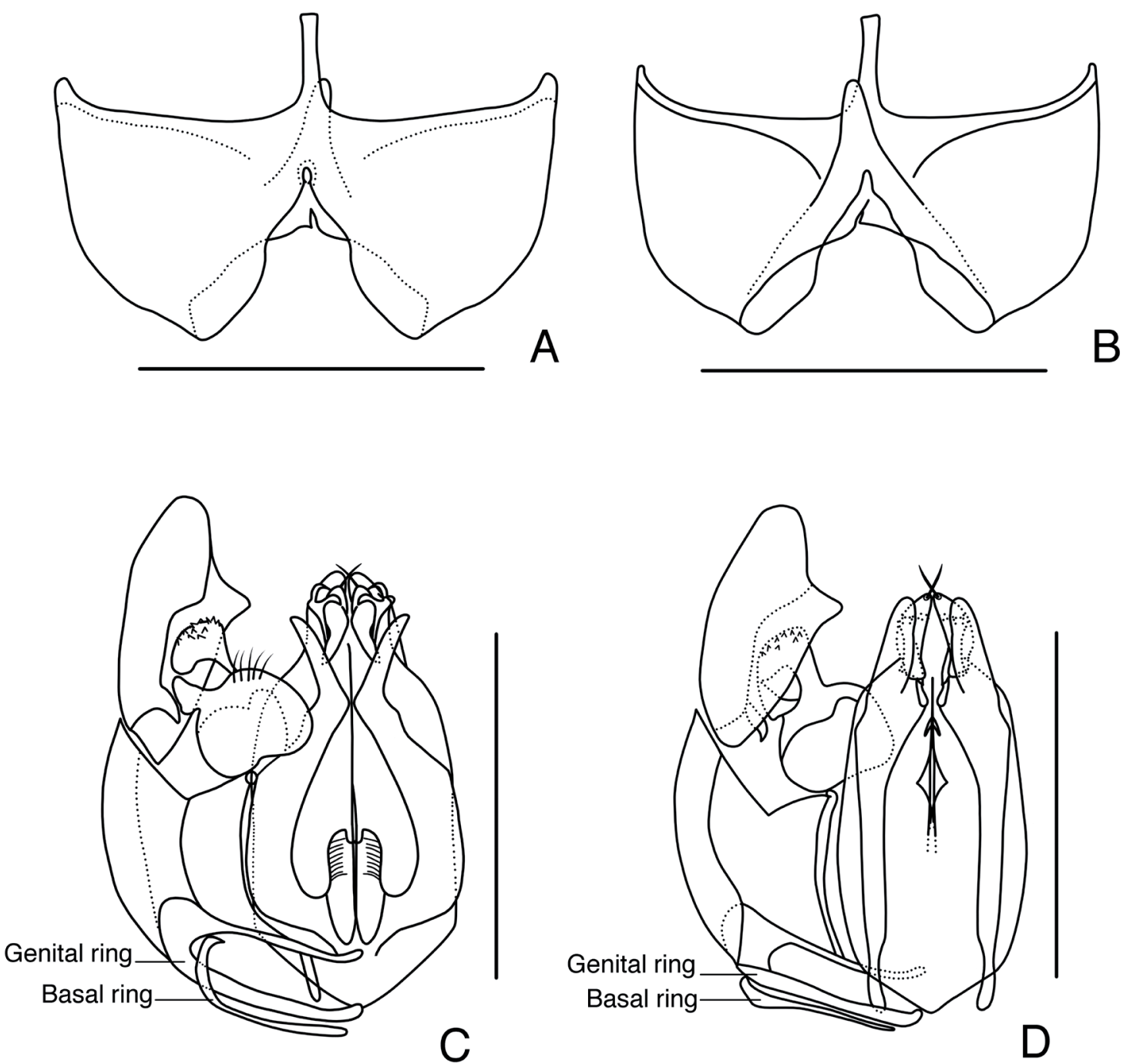

Fig. 6. Apenesia tagala comb. nov., holotype, $\widehat{\jmath}$. A. Hypopygium, outer view. B. Hypopygium, inner view. C. Genitalia, ventral view. D. Genitalia, dorsal view (bars $0.5 \mathrm{~mm}$ ). 
Kieffer (1913) misidentified the sex of the holotype of Neurepyris rufiventer as a female. However, the specimen is clearly a male. There are two identification labels attached to the type, one is Epyris rufiventer and the other is Neurepyris rufiventer. However this specimen has never been formally named as Epyris rufiventer. That indicates a probable confusion about the concept of the genus within Epyrini by the author species, although both Neurepyris and Epyris are classified as Epyrini.

Neurepyris rufiventer is easily recognized as belonging to Pristocerinae mostly because it has the metanotum well developed medially. It also has the hypopygium deeply divided into two lobes. Such a condition is found in five genera of this subfamily: Dicrogenium Stadelmann, 1894, Neodicrogenium Benoit, 1957, Diepyris Benoit, 1957, Kathepyris Kieffer, 1907 and Pristocera. Among these genera, the first two have a large spine on the genal area which makes them distinct. Diepyris has the mandible sickle-shaped with only two apical teeth, whereas Kathepyris and Pristocera have mandibles that are wide apically, with four or five apical teeth. However, Kathepyris has the forewings with subdiscoidal and cubital veins reaching the apical margin of the wing whereas Pristocera does not. Neurepyris rufiventer should certainly be assigned to Pristocera because it has the combination of the following characters: the mandibles wide apically with five apical teeth, the genal area without spine, the forewings with subdiscoidal and cubital veins barely visible and not reaching apical margin of the wing, and the hypopygium divided into two lobes. Because of that we propose the transference of Neurepyris rufiventer to Pristocera and the subsequent new combination (P. rufiventer comb. nov.).

Neurepyris tagala was originally described as a species belonging to Epyris Westwood, 1832 (see Ashmead 1905). However Kieffer (1908) transferred it to Rhabdepyris and indicated a possible confusion about the generic identity of this species. Finally it was transferred to Neurepyris by Kieffer (1914a). Nevertheless, both transferences remained within Epyrini genera. However, what first called our attention is the fact $N$. tagala presents the metanotum well developed medially as it occurs in all Pristocerinae. Actually, this condition is pointed out as the main synapomorphy of this subfamily (Sorg 1988; Terayama 1996). Neurepyris tagala has the basal tooth of the mandible not curved inwardly, the median lobe of clypeus not depressed near the antennal insertions, and the aedeagus consisting of one lamina. This combination of characters addresses this species to Apenesia Westwood. Because of that we propose the transference of Neurepyris tagala and the subsequent new combination (Apenesia tagala comb. nov.).

According to Gordh \& Móczár (1990), N. tagala was designated the type species of Neurepyris by 'subsequent monotypy'. However, this assumption does not fit with the nomenclatural history of the genus.

Neurepyris was established by Kieffer (1905) in a key. He did not provide any description nor include any species on it. Curiously, Kieffer \& Marshall (1904-1906) mentioned that Neurepyris was created to accommodate one species from Eritrea known only from one single female (see the footnote in Kieffer \& Marshall's key, page 251). However, there was no species formally addressed to Neurepyris in that time. Kieffer (1908) formally described Neurepyris and pointed out that "l'espèce... sur lequel ce genre est etabli provient de l'Erythree et n'a pas encore ete decrit" (= this genus was established based one species from Eritrea not described yet). Kieffer (1913) formally provided the description of the first species of Neurepyris, N. rufiventer, the species from Eritrea. Kieffer (1914a) transferred Rhabdepyris (Trichotepyris) tagala (Ashmead, 1905), previously described in Epyris, to Neurepyris. He also indicated Neurepyris rufiventer as the type species of this genus.

Given this scenario, we offer three conclusions. First it is clear N. rufiventer is the type species by subsequent monotypy in Kieffer (1913), second the indication of type species by Kieffer (1914a) was unnecessary, and third the citation of $N$. tagala as type species by Gordh \& Móczár (1990) is not 
adequate. So we assume that the correct type-species of the genus is Neurepyris rufiventer. Thus it has to be treated as a new junior synonym of Pristocera.

\section{Acknowledgement}

We thank to Fabio Penati (MCSN) and David Furth (USNM) for the loan of the types and other support, Matthias Buffington for taking the pictures of the genitalia of Neurepyris tagala, Diego N. Barbosa for taking some pictures of Neurepyris rufiventer, Felipe B. Fraga for his help with the genitalia draws of Neurepyris rufiventer, CAPES and CNPq (grants \#500280/00-8, \#303216/2004-2, \#306331/20077 and \#306231/2007-7) by providing scholarship to the authors and financial support; CNPq for the Programa Casadinho grant \#620064/2006-4 and \#620068/2008-6, and Programa de Taxonomia grant \#563953/05-5 by providing additional financial support.

\section{References}

Ashmead W.H. 1905. New Hymenoptera from the Philippine Islands. Proceedings of the United States National Museum 29: 107-119.

Azevedo C.O. 1999. Revision of the Neotropical Dissomphalus Ashmead, 1893 (Hymenoptera, Bethylidae) with median tergal processes. Arquivos de Zoologia 35: 301-394.

Benoit P.L.G. 1957. Hymenoptera - Bethylidae. Exploration du Parc National Albert, Mission G. F. De Witte, 1933-1935, vol. 88. Institut des Parcs Nationaux du Congo Belge, Bruxelles.

Brown R.E. 1906. A catalogue of Philippine Hymenoptera, with description of new species. Philippine Journal of Science 1: 683-695.

Evans H.E. 1964. A synopsis of the American Bethylidae (Hymenoptera, Aculeata). Bulletin of the Museum of Comparative Zoology 132: 1-222.

Gordh G. \& Móczár L. 1990. A catalog of the world Bethylidae (Hymenoptera). Memoirs of the American Entomological Institute 46: 1-364.

Harris R.A. 1979. A glossary of surface sculpturing. Occasional Papers in Entomology 28: 1-31.

Kieffer J.J. \& Marshall T.A. 1904-1906. Tome IX. Proctotrypidae. In: André E. (ed.) Species des Hyménoptères d'Europe \& d'Algérie: 1-552. Paris.

Kieffer J.J. 1905. Description de nouveaux Proctotrypides exotiques. Annales de la Société Scientifique de Bruxelles 29: 95-142.

Kieffer J.J. 1907. Beschreibung neuer in British Museum zu London Aufbewahrter Proctotrypiden. Berliner Entimilogische Zeitschrift 51: 279-302.

Kieffer J.J. 1908. Bethylidae. Genera Insectorum 76: 1-50.

Kieffer J.J. 1913. Nouveaux microhyménoptères de l'Afrique équatoriale. Bollettino del Laboratorio di Zoologia General e Agraria, Portici 7: 105-112.

Kieffer J.J. 1914a. Bethylidae. Das Tirreich 41: 1-595. http://dx.doi.org/10.5962/bhl.title.1095

Kieffer J.J. 1914b. Enumération des Serphides (Proctotrupides) des iles Philippines avec description de genres nouveaux et d'espèces nouvelles. Philippine Journal of Science 9: 285-311.

Klug F. 1808. Uber die Geschlechtsverschiedenheit der Piezaten. Erste Halfte der Fabriciusschen Gattungen. Magazin Gesellschaft naturfoschender freunde 2: 48-63.

Kurian C. 1954. Catalogue of Oriental Bethyloidea. Agra University Journal of Research 3: 253-288. 
Sorg M. 1988. Zur Phylogenic und Systematik der Bethylidae (Insecta: Hymenoptera: Chrysidoidea). Sonderveröffentlichungen des Geologisches Institut der Universitat zu Köln 63: 1-146.

Stadelmann H. 1894. Eine neue Hymenopterengattung aus der Familie der Prototrupiden. Entomologische Nachrichten 20: 199-202.

Terayama M. 1996. The phylogeny of the Bethylid wasp subfamily Pristocerinae (Hymenoptera, Bethylidae). Japanese Journal of Entomology 64: 587-601.

Westwood J.O. 1832. Descriptions of several new British forms amongst the parasitic hymenopterous insects. London and Edinburgh Philosophical Magazine and Journal of Science 1: 127-129. http:// dx.doi.org/10.1080/14786443208647849

Westwood J.O. 1874. Thesaurus Entomologicus Oxoniensis. Clarendon Press, Oxford.

Manuscript received: 13 August 2011

Manuscript accepted on: 16 November 2011

Published on: 28 December 2011

Topic editor: Malcolm Scoble.

In compliance with Article 8.6 of the ICZN, printed versions of all papers are deposited in the libraries of the institutes that are members of the EJT consortium. 